BUDGETING : Journal of Business, Management and Accounting

Volume 2, Nomor 2, Januari-Juni 2021

e-ISSN: 2715-2480

p-ISSN: $2715-1913$

DOI: https://doi.org/10.31539/budgeting.v2i2.1755

\title{
MINAT BELI BERDASARKAN CREATIVE PROMOTION DAN INOVASI PRODUK
}

\author{
Selvia Ramdani ${ }^{1}$, R. Deni M. Danial ${ }^{2}$, Nor Norisanti ${ }^{3}$ \\ Universitas Muhammadiyah Sukabumi ${ }^{1,2,3}$ \\ acil.selvia@gmail.com ${ }^{1}$
}

\begin{abstract}
ABSTRAK
Tujuan penelitian ini adalah untuk mengetahui pengaruh creative promotion dan inovasi produk terhadap minat beli pada Aneka Bolu Alam Jaya Kota Sukabumi. Metode yang digunakan dalam penelitian ini adalah metode sistem random sampling, dimana penulis menyebarkan kuisioner terhadap 86 konsumen. Teknik analisis yang digunakan penulis adalah menggunakan teknik analisis regresi linear berganda, koefesien korelasi ganda dan koefesien determinasi. Hasil penelitian menggunakan uji koefesien determinasi menunjukan nilai Adjuster $\mathrm{R}^{2}$ adalah sebesar 0,518 yang berarti analisis creative promotion dan inovasi produk terhadap minat beli adalah 52,9\% dan 47,1\% dipengaruhi oleh faktor lain yang tidak diteliti. Selain itu, pengujian koefesien korelasi ganda menunjukkan nilai $\mathrm{R}$ sebesar 72,8 yang berarti terjadi hubungan yang kuat antara creative promotion dan inovasi produk terhadap minat beli. Berdasarkan hasil uji $\mathrm{F}$ yang telah dilakukan, ditemukan nilai sig. $0,000<0,05$. Simpulan, creative promotion dan inovasi produk berpengaruh secara positif dan signifikan secara bersama-sama terhadap minat beli konsumen.
\end{abstract}

Kata Kunci : Creative Promotion, Inovasi Produk, Minat Beli

\section{ABSTRACT}

This study aimed to determine the effect of creative promotion and product innovation on buying interest in various Bolu Alam Jaya, Sukabumi City. The method used in this study is a random sampling system method, where the authors distribute questionnaires to 86 consumers. The author's analysis technique is to use multiple linear regression analysis techniques, multiple correlation coefficient, and coefficient of determination. The study results using the coefficient of determination test showed that the value of Adjuster $R 2$ was 0.518 , which means that the analysis of creative promotion and product innovation on purchase intention was $52.9 \%$ and $47.1 \%$ were influenced by other factors not examined. Besides, the multiple correlation coefficient tests show an $R$-value of 72.8, which means a strong relationship between creative promotion and product innovation on purchase interest. Based on the $F$ test results that have been carried out, the sig value is found. $0.000<0.05$. In conclusion, creative promotion and product innovation positively and significantly affect consumer purchase interest.

Keywords: Creative Promotion, Product Innovation, Purchase Interest 


\section{PENDAHULUAN}

Usaha Mikro, Kecil dan Menengah (UMKM) merupakan stimulan perekonomian pada negara berkembang. Terdapat keunggulan-keunggulan UMKM dibandingkan dengan usaha besar, diantaranya yaitu: 1) inovasi dalam teknologi yang telah dengan mudah terjadi dalam pengembangan produk; 2) berbasis pada sumber daya lokal sehingga dapat memanfaatkan potensi secara maksimal dan memperkuat kemandirian; 3) kemampuan menciptakan lapangan kerja cukup banyak atau penyerapan tenaga kerja; 4) fleksibilitas dan kemampuan menyesuaikan diri terhadap kondisi pasar dengan cepat dibandingkan dengan perusahaan dalam skala besar yang pada umumnya birokratis; 5) terdapat dinamisme manajerial dan peranan kewirausahaan; 6) dimiliki dan dilaksanakan oleh masyarakat lokal sehingga mampu mengembangkan sumber daya manusia; 7) tersebar dalam jumlah yang banyak sehingga merupakan alat pemerataan pembangunan yang efektif (Hafni \& Rozali, 2015).

Banyak perusahaan yang sudah terdata oleh Dinas Perdagangan, Koperasi Usaha Kecil dan Menengah (DPKUKM) di bawah naungan Pemerintah. Di Kabupaten Sukabumi keberadaan Usaha Mikro, Kecil dan Menengah (UMKM) sangat beragam. Dari data DPKUKM Kabupaten Sukabumi, Jawa Barat; mencatat ada sekitar 24.159 pelaku UMKM dalam berbagai sektor (Japar, 2018). Salah satu UKM yang bergerak di bidang penyedia produk di Kota Sukabumi adalah UKM Aneka Bolu Alam Jaya. UKM ini bergerak dalam memasarkan aneka makanan, seperti Bolu, Donat dan Kue Basah.

Aneka Bolu Alam Jaya masih berusaha bertahan dalam persaingan kuliner dengan banyak kompetitor lain karena sudah banyak sekali perusahaan lain yang menyediakan produk yang hampir sama. Dalam melakukan promosinya, Aneka Bolu Alam Jaya memanfaatkan media sosial, diantaranya Facebook, Instagram, Blog dan Whatsapp. Kemudian ditengah persaingan kualitas produk, Aneka Bolu Alam Jaya menggunakan mesin Bakery. Hal tersebut dilakukan karena mesin Bakery berpengaruh baik pada saat pengadukan adonan dan pemanggangannya, sehingga menghasilkan produk yang berkualitas baik.

Minat beli bermasalah diduga karena kurang baiknya dalam mempromosikan produk, yaitu tekniknya yang kurang maksimal. Strategi pemasaran yang monoton membuat produk tidak dapat terpublikasikan dengan baik kepada calon konsumen. Kemudian hal tersebut tidak didukung dengan proses inovasi produk karena terletak 
pada perluasan lini yang kurang baik. Produk yang diciptakan cenderung memiliki kualitas yang hampir sama dengan produk yang lainnya. Sehingga kondisi tersebut memerlukan strategi pemasaran yang baik dan modifikasi produk menjadi lebih menarik. Oleh karena itu, peneliti tertarik untuk mengukur analisis creative promotion dan inovasi produk terhadap minat beli pada Aneka Bolu Alam Jaya Kota Sukabumi.

\section{KAJIAN TEORI}

\section{Creative Promotion}

Creative promotion adalah salah satu hal yang menarik perhatian dari suatu organisasi atau perusahaan, jasa yang ditawarkan, acara atau kampanye yang dijalankan, atau beberapa isu atau sebab sponsor, dan lakukanlah hal ini dengan cara positif yang nantinya akan diperhatikan dan diingat masyarakat. Promosi yang kreatif menggunakan strategi komunikasi pemasaran terpadu yaitu suatu sinergi, kreativitas, integrasi dan komunikasi pemasaran secara terpadu dengan cara memanfaatkan beragam elemen komunikasi yang berbeda-beda agar tercipta koherensi yang saling mendukung (Rangkuti, 2009).

Creative promotion dapat diukur melalui indikator: 1) ide dasar, merupakan rancangan yang telah disusun mengenai strategi promosi; 2) teknik, merupakan langkah pengaplikasian dari ide dasar. Teknik yang kreatif memiliki daya cipta, mempunyai kemampuan untuk mencipatakan atau mampu menciptakan sesuatu yang baru dan relatif berbeda dengan apa yang telah ada sebelumnya; 3) evaluasi, yaitu langkah memperbaiki ide dasar dan teknik creative promotion.

\section{Inovasi Produk}

Inovasi produk adalah kemampuan perusahaan untuk menghasilkan produk sesuai keinginan pelanggan. Inovasi produk merupakan sesuatu yang dapat dilihat sebagai kemajuan fungsional produk yang dapat membawa produk selangkah lebih maju dibandingkan dengan produk pesaing (Dewi, 2006).

Lukas \& Ferrel (2000) mengemukakan dimensi inovasi produk meliputi: 1) perluasan lini (line extensions) yaitu produk yang dihasilkan perusahaan tidaklah benarbenar baru tetapi relatif baru untuk sebuah pasar; 2) produk baru (me too-product) yaitu produk baru bagi perusahaan tetapi tidak baru bagi pasar; 3) produk benar-benar baru 
(new to the world product) adalah produk yang termasuk baru baik bagi perusahaan maupun pasar.

\section{Minat Beli}

Minat konsumen yaitu salah satu faktor penentu utama suatu perusahaan yang harus diperhatikan. Minat konsumen juga merupakan suatu kebutuhan bagi perusahaan yang dapat didefinisikan sebagai sesuatu yang dibutuhkan untuk mencapai tujuan perusahaan. Menurut (Durianto, 2003) minat beli merupakan sesuatu yang berhubungan dengan rencana konsumen untuk membeli produk tertentu, serta berapa banyak unit produk yang dibutuhkan pada periode tertentu.

Minat beli adalah tahap kecenderungan responden untuk bertindak sebelum keputusan membeli benar-benar dilaksanakan (Fitriana, 2013). Minat beli dapat diidentifikasi melalui dimensi-dimensi sebagai berikut: 1) pencarian informasi lanjut, 2) kemauan untuk memahami produk; 3) keinginan untuk mencoba produk; 4) kunjungan ke outlet.

Menurut Setiawati (2017) hubungan analisis creative promotion dan inovasi produk terhadap minat adalah berpengaruh signifikan terhadap keputusan pembelian. Analisis pengaruh promosi penjualan, inovasi produk terhadap keputusan pembelian dan dampaknya terhadap loyalitas telah dilakukan oleh Santoso \& Samboro (2017). Hasil yang ditemukan oleh keduanya adalah promosi penjualan, inovasi produk pada keputusan pembelian dan dampaknya berpengaruh signifikan terhadap loyalitas.

\section{METODE PENELITIAN}

Penelitian ini dilaksanakan di Aneka Bolu Alam Jaya Kota Sukabumi dengan menggunakan metode sampling dengan teknik samplingnya yaitu simple random sampling dan melakukan penyebaran kuesioner terhadap 86 konsumen Aneka Bolu Alam Jaya Kota Sukabumi. Teknik analisis yang digunakan dalam penelitian ini yaitu teknik analisis regresi berganda dan melakukan pengujian hipotesis secara Simultan (Uji F). 


\section{HASIL PENELITIAN}

\section{Hasil Analisis Regresi Linear Berganda}

Regresi linear berganda berguna untuk meneliti seberapa besar pengaruh beberapa variabel yang berkorelasi dengan variabel yang diuji (creative promotion (X1); inovasi produk (X2); minat beli (Y)). Berikut ini merupakan hasil dari regresi linear berganda yang ditunjukan pada tabel 1 .

Tabel 1.

Hasil Uji Regresi Linear Berganda

\begin{tabular}{|c|c|c|c|c|c|c|}
\hline \multicolumn{7}{|c|}{ Coefficients $^{a}$} \\
\hline & \multirow{2}{*}{ Model } & \multicolumn{2}{|c|}{ Unstandardized Coefficients } & \multirow{2}{*}{$\frac{\text { Standardized Coefficients }}{\text { Beta }}$} & \multirow{2}{*}{$\mathbf{t}$} & \multirow{2}{*}{ Sig. } \\
\hline & & $\mathbf{B}$ & Std. Error & & & \\
\hline \multirow{3}{*}{1} & $($ Constant $)$ & 2.935 & 1.132 & & 2.593 & .011 \\
\hline & $\mathrm{X} 1$ & .105 & .052 & .191 & 2.027 & .046 \\
\hline & $\mathrm{X} 2$ & .414 & .065 & .597 & 6.356 & .000 \\
\hline
\end{tabular}

a. Dependent Variable: Y

(Sumber : Data Primer (Kuesioner), 2019)

Berdasarkan hasil uji regresi linear berganda di atas, dapat diperoleh persamaan sebagai berikut:

$$
Y=2,935+0,105 X_{1}+0,414 X_{2}
$$

\section{Koefesien Determinasi $\left(\mathbf{R}^{2}\right)$}

Tabel 2.

Hasil Koefesien Determinasi

\begin{tabular}{ccccc}
\hline \multicolumn{5}{c}{ Model Summary } \\
\hline Model & R & R Square & Adjusted R Square & Std. Error of the Estimate \\
\hline 1 & $.728^{\mathrm{a}}$ & .529 & .518 & 1.787 \\
\hline a. Predictors: $($ Constant $), \mathrm{X} 2, \mathrm{X} 1$ & &
\end{tabular}

(Sumber : Data Primer (Kuesioner), 2019)

Hasil tabel 2 menunjukan besarnya nilai Adjusted $\mathrm{R}^{2}$ adalah 0,518 . Hal tersebut menunjukan 51,8\% variabel keputusan pembelian dapat dijelaskan oleh kedua variabel independen yaitu creative promotion dan inovasi produk. Sementara $47,1 \%$ berasal dari faktor yang tidak diteliti dalam penelitian. 
Koefesien Korelasi Ganda (R)

Tabel 3.

Hasil Koefesien Korelasi Ganda

\begin{tabular}{ccccc}
\hline \multicolumn{4}{c}{ Model Summary } \\
\hline Model & R & R Square & Adjusted R Square & Std. Error of the Estimate \\
\hline 1 & $.728 \mathrm{a}$ & .529 & .518 & 1.787 \\
\hline a. Predictors: (Constant), X2, X1 & & \\
\hline (Sumber : Data Primer (Kuesioner), 2019) &
\end{tabular}

Berdasarkan tabel 3 diatas diperoleh angka $\mathrm{R}$ Sebesar 0,728 berada pada kategori 0,60-0,799. Hal ini menunjukan bahwa hubungan yang terjadi antara creative promotion dan inovasi produk dengan minat beli terbilang kuat.

\section{Uji Signifikasi Secara Farsial (Uji F)}

Tabel 4.

Hasil Uji F

\begin{tabular}{llllllr}
\hline \multicolumn{7}{c}{ ANOVA $^{\text {a }}$} \\
\hline \multirow{2}{*}{1} & Model & Sum of Squares & Df & Mean Square & F & Sig. \\
\cline { 2 - 7 } & Regression & 298.263 & 2 & 149.132 & 46.700 & $.000 \mathrm{~b}$ \\
\cline { 2 - 7 } & Residual & 265.051 & 83 & 3.193 & & \\
\cline { 2 - 6 } & Total & 563.314 & 85 & & & \\
\hline
\end{tabular}

a. Dependent Variable: Y

b. Predictors: (Constant), X2, X1

(Sumber : Data Primer (Kuesioner), 2019)

Berdasarkan tabel 4 diatas, hasil uji $\mathrm{F}$ yang dilakukan dapat diperoleh nilai sig. $0,000<0,05$; nilai $F_{\text {hitung }} 46,700>F_{\text {tabel }} 3,95$. Hasil ini menunjukan bahwa creative promotion dan inovasi promosi berpengaruh secara simultan terhadap minat beli.

\section{PEMBAHASAN}

Keunikan produk berpengaruh secara positif dan signifikan terhadap keputusan pembelian (Y) secara parsial. Hal ini berdasarkan hasil pengujian t yang menunjukan nilai sig. $0,000<0,05$; nilai thitung 3,95 dapat disimpulkan bahwa $\mathrm{H}_{1}$ diterima. Hal ini menunjukan bahwa creative promotion yang ada di perusahaan memberikan nilai positif dalam mempengaruhi minat beli.

Creative promotion dan inovasi produk berpengaruh positif dan signifikan terhadap keputusan pembelian (Y) secara simultan. Hal ini dibuktikan dengan hasil pengujian $F$ menunjukkan nilai sig. $0,000<0,05$; nilai $F_{\text {hitung }} 46,700>F_{\text {tabel }} 3,95$. Hal ini 
menunjukan bahwa keunikan produk dan word of mouth berpengaruh signifikan secara simultan terhadap keputusan pembelian. Hasil ini sejalan dengan temuan Firatma \& Maskan (2016) bahwa secara simultan terdapat pengaruh yang signifikan antara variabel inovasi produk dan promosi penjualan terhadap keputusan pembelian. Selain itu Maulana \& Alisha (2020) juga menemukan bahwa inovasi produk berpengaruh terhadap minat beli konsumen. Dengan demikian semakin meningkatnya nilai inovasi produk, maka nilai minat beli konsumen juga akan semakin meningkat.

Inovasi menjadi faktor dominan dalam mempertahankan daya saing di seluruh dunia. Hal ini mendorong pertumbuhan organisasi, mendorong kesuksesan di masa depan dan merupakan bentuk pembaharuan yang memungkinkan bisnis untuk mempertahankan kelangsungan hidup mereka dalam ekonomi global (Husti \& Mahyarni, 2019). Terciptanya sebuah inovasi produk diharapkan perusahaan dapat menempati posisi strategis di pasar, memiliki life cycle yang lebih panjang dan dapat menahan serangan dari para pesaing serta dapat memenuhi keinginan pasar (konsumen).

\section{Analisis Creative Promotion $\left(\mathrm{X}_{1}\right)$ Inovasi Produk $\left(\mathrm{X}_{2}\right)$ terhadap Minat Beli (Y)}

Berdasarkan hasil yang didapat melalui analisis data pada uji $\mathrm{t}$ creative promotion dengan minat beli menunjukan bahwa creative promotion yang diterapkan di Aneka Bolu Alam Jaya belum begitu maksimal sehingga membuat konsumen kurang berminat membeli produk aneka bolu alam jaya. Padahal menurut Suharsono \& Sari (2019) promosi berpengaruh cukup besar terhadap keputusan pembelian konsumen. Promosi merupakan suatu cara yang dilakukan untuk menginformasikan deskripsi suatu barang ataupun jasa yang sedang ditawarkan agar konsumen terkait mengenal dan kemudian membeli. Merujuk dari beberapa pendapat tersebut, maka promosi sendiri dapat diartikan sebagai suatu usaha seseorang atau perusahaan untuk mempengaruhi, merayu atau membujuk konsumen untuk mengenal lebih tentang manfaat produk yang ditawarkan, sehingga dengan pemahaman akan fungsi dari produk tersebut, konsumen akan terdorong untuk melakukan pembelian.

\section{SIMPULAN}

Creative promotion dan inovasi berpengaruh positif dan signifikan secara simultan terhadap Minat Beli pada Aneka Bolu Alam Jaya Sukabumi. 


\section{DAFTAR PUSTAKA}

Dewi, S. T. (2006). Analisa Pengaruh Orientasi Pasar dan Inovasi Produk terhadap Keunggulan Bersaing untuk Meningkatkan Kinerja Pemasaran. Jurnal Magister Manajemen Universitas Diponegoro, 6(1), 102-111

Durianto, D. (2003). Inovasi Pasar dengan Iklan Efektif. Jakarta: Cetakan Gramedia Pustaka

Firatma, M. D., \& Maskan, M. (2016). Pengaruh Inovasi Produk dan Promosi Penjualan terhadap Keputusan Konsumen pada Dea Cake and Bakery Malang. Jurnal Aplikasi Bisnis, 2(1), 73-76

Fitriana, S. (2013). Pengaruh Efektivitas Iklan terhadap Minat Beli yang Dimediasi oleh Citra Merek. Skripsi. Universitas Muhammadiyah Surakarta

Hafni, R., \& Rozali, A. (2015). Analisis Usaha Mikro, Kecil dan Menengah (UMKM) terhadap Penyerapan Tenaga Kerja di Indonesia. Ekonominawan, Jurnal Ilmu Ekonomi dan Studi Pembangunan, 15(2), 77-96

Husti, I., \& Mahyarni, M., 2019. Islamic Leadership, Innovation, Competitive Advantages and Performance of SMEs in Indonesia. East Asia 36(1), 369-383

Japar, A. (2018). Usaha Mikro Dominasi UMKM di Sukabumi. https://megapolitan.antaranews.com/berita/46322/usaha-mikro-dominasi-umkmdi-sukabumi

Lukas, B. A., \& Ferrell, O. C. (2000). The Effect of Market Orientation on Product Innovation. Journal of the Academy of Marketing Science, 28(1), 239-247

Maulana, Y. S., \& Alisha, A. (2020). Inovasi Produk dan Pengaruhnya Terhadap Minat Beli Konsumen (Studi Kasus pada Restoran Ichi Bento Cabang Kota Banjar). Inovbiz: Jurnal Inovasi Bisnis, 8(1), 86-91

Rangkuti, F. (2009). Strategi Promosi yang Kreatif dan Analisis Kasus Integrated Marketing Communication. Jakarta: PT. Gramedia PustakaUtama

Santoso, E. B., \& Samboro, J. (2017). Pengaruh Promosi Penjualan dan Inovasi Produk terhadap Keputusan Pembelian dan Dampaknya terhadap Loyalitas Pelanggan. Jurnal Administrasi dan Bisnis, 11(1), 1-8

Setiawati, Y. R. (2017). Pengaruh Kreativitas Iklan terhadap Minat Beli Produk Minuman “Teh Yen Yen”. Skripsi. Universitas Sanata Dharma Yogyakarta

Suharsono, R. S., \& Sari, R. P. (2019). Pengaruh Promosi Media Online terhadap Keputusan Pembelian Produk Hijab (Studi pada Alif Galeri Hijab Sidoarjo). Jurnal Aplikasi Manajemen dan Inovasi Bisnis, 1(2), 41-54 